\title{
Os Sítios Arqueológicos Guarani do Município de Iepê, estado de São Paulo
}

Neide Barrocá Faccio(*)

FACCIO, N.B. Os Sítios Arqueológicos Guarani do Município de Iepê, estado de São Paulo. R. Museu Arq. Etn., 25: 119-131, 2015

Resumo: A pesquisa realizada na área de sete sítios arqueológicos do Município de Iepê, localizado na região da Bacia do Rio Paranapanema (afluente da Bacia do Paraná), Estado de São Paulo, demonstrou ocupações guarani pré-coloniais. A cerâmica foi datada por termoluminescência, situando as ocupações no período de 700 a 1668 anos antes do presente. Este trabalho traz dados referentes à cerâmica confrontados com dados de outras pesquisas disponíveis que versaram sobre a presença dos Guarani na Bacia do Paraná e Paranapanema.

Palavras-chave: Arqueologia Guarani; análise cerâmica; Bacia do Rio Paranapanema

\section{Introdução}

Edivulgada no Brasil, a arqueologia está presente em, praticamente, todas as nossas regiões e, certamente, tem visto crescer sua importância nos últimos anos. Na região do Vale do Rio Paranapanema, lado paulista - objeto específico deste estudo - pesquisas arqueológicas acontecem desde a década de 1960. Destacamos, nesse crescente reconhecimento social da arqueologia, sua participação obrigatória nos processos de licenciamento ambiental, normatizados pelas portarias IPHAN 7/1988 e 230/2002.

A etno-história da região do Vale do Rio Paranapanema, lado paulista, aponta para a presença de grupos Guarani, Kaingang e Xavante. Contudo, até o momento foram encontrados somente vestígios de grupos Guarani

(*) UNESP, Campus de Presidente Prudente, Laboratório de Arqueologia Guarani < nfaccio@terra.com.br> e Kaingang. Tratamos, neste artigo, da análise de sete sítios de grupos indígenas guarani, encontrados no Munícipio de Iepê, SP. Essas ocupações datam de 700 a 1.668 anos antes do presente.

O Estado de São Paulo foi densamente povoado por índios grupos indigenas, cuja presença era marcante no Vale do Paranapanema, até o início do século XX. Os sete sítios arqueológicos estudados no município de Iepê, SP estão localizados próximo à margem paulista do Rio Paranapanema, não distantes uns dos outros, numa extensão de 10.800 metros.

Desses sítios, pudemos conhecer apenas parte de suas áreas, tendo em vista não sabermos o quanto de cada um deles está submerso nas águas do Lago da Hidrelétrica da Capivara. Mesmo em períodos de seca, quando o nível desse lago baixa até 10 metros, eles não emergem totalmente. Tais sítios se inserem no que Morais (2002) define como sistema regional de ocupação de agricultores, perspectiva teórico-metodológica que adotamos para sua contextualização. 
Nesse trabalho, apresentamos o estudo de sete sítios arqueológicos localizados em lepê, região do Baixo Vale do Rio Paranapanema. São eles: Lagoa Seca, Aguinha, Terra do Sol Nascente, Pernilongo, Ragil, Ragil II e Capisa. As figuras 1 e 2 mostram, respectivamente, a localização dos sítios antes e depois da formação do lago da UHE da Capivara. A maior parte desses sítios apresentou grande quantidade de materiais cerâmicos, líticos lascados, líticos polidos, urnas funerárias, manchas pretas e adornos em resina de jatobá. Buscamos realizar uma sistemática e criteriosa arqueografia desses materiais, embora os sítios não possam
- devido à sua localização intermitentemente submersa - ser exaustivamente pesquisados em sua totalidade. Outros dois sítios líticos, provavelmente da Tradição Umbu, Vallone e Roberto Ekman Simões, encontrados nessa mesma área, não são alvo desse artigo.

Em Iepê foi montado o Museu de Arqueologia de Iepê (MAI) por demanda da população local, numa parceria entre a FCT/UNESP, o ProjPar (Projeto Paranapanema), o MAE/ USP e a Prefeitura Municipal de Iepê, SP. Quando nos referimos à população local, não posso deixar de citar Roberto Ekman Simões que, enquanto vivo, não mediu esforços para

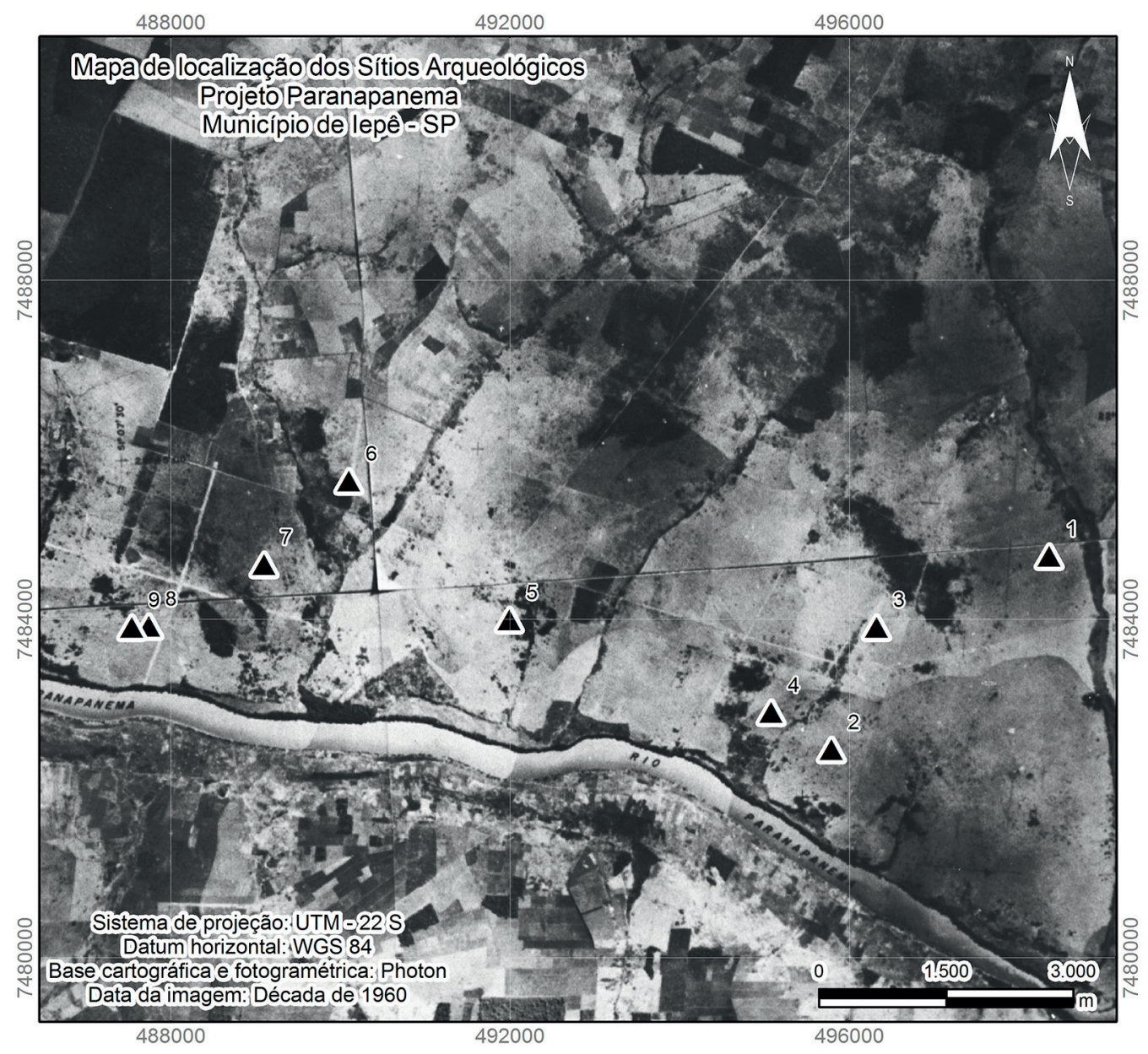

Fig. 1. Localização dos sítios arqueológicos de Iepê, SP em 1960, antes da formação do lago da UHE da Capivara. Legenda: 1- Ragil II, 2 - Capisa, 3-Ragil, 4 - Vallone, 5-Pernilongo, 6- Terra do Sol Nascente, 7-Aguinha, 8 - Lagoa Seca e 9- Roberto Ekman Simões. 


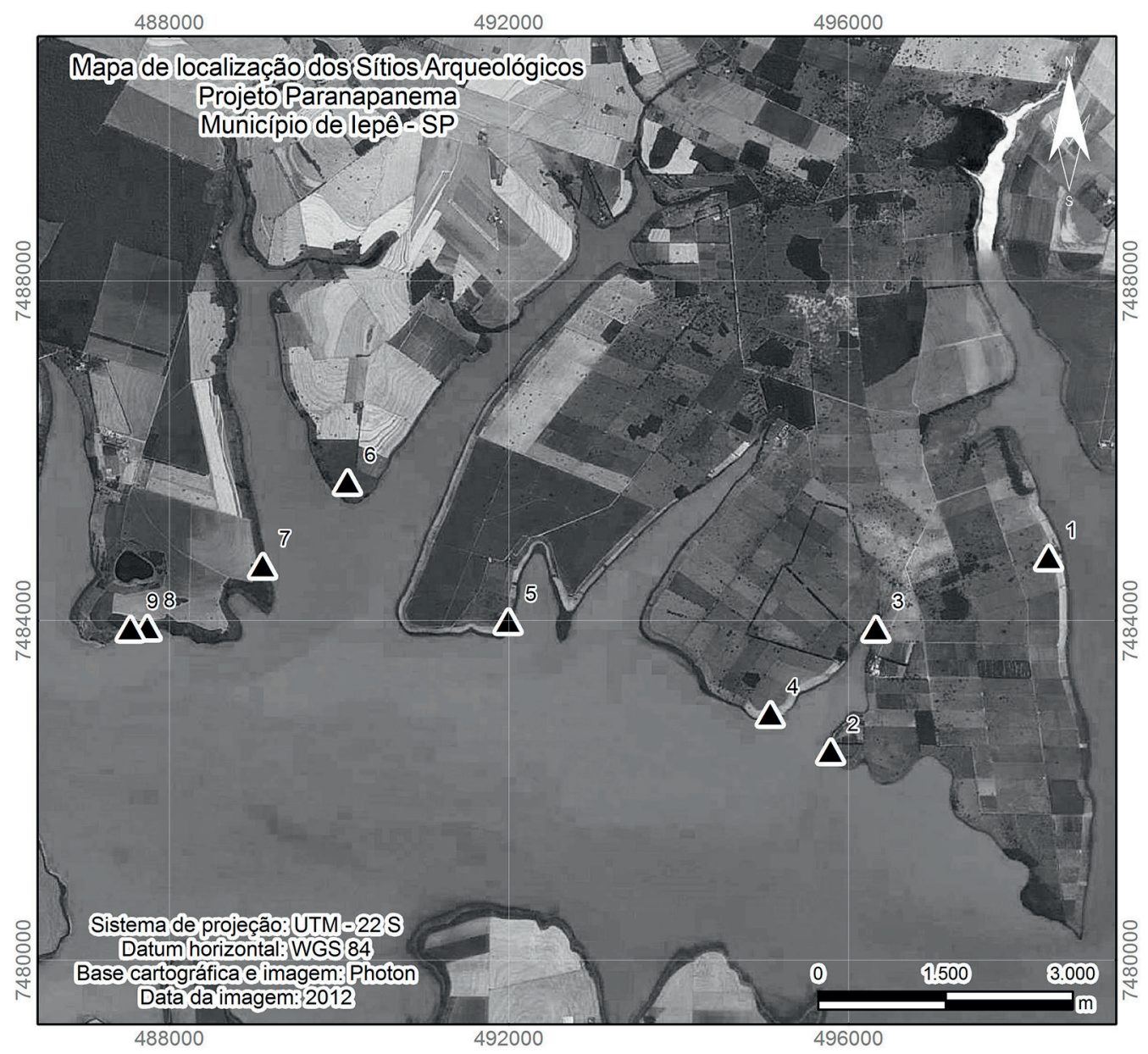

Fig. 2. Localização dos sítios arqueológicos de Iepê, SP em 2012, depois da formação do lago da UHE da Capivara. Legenda: 1- Ragil II, 2 - Capisa, 3- Ragil, 4 - Vallone, 5- Pernilongo, 6- Terra do Sol Nascente, 7 Aguinha, 8 - Lagoa Seca e 9- Roberto Ekman Simões.

que seu sonho de organizar um museu em Iepê se tornasse realidade. Essa nota acaba sendo extensiva à sua família, que continuou seu legado de empenho e tem se mostrado parceira no desenvolvimento das atividades do Museu.

Tendo em vista que a grande maioria do material resgatado estava em pedaços e um museu precisa, sobretudo, de peças inteiras, para chamar a atenção do público e mostrar as formas das peças que os índios produziram, desenvolvemos e aplicamos largamente algumas técnicas de restauro. O Museu de Arqueologia de Iepê tem se consolidado como um espaço que cumpre o papel de mantenedor da memó- ria, contada por meio de objetos, a partir de interlocutores do conhecimento produzido na universidade.

O trabalho na área dos sítios de Iepê, SP acontece desde 1998, sempre que o nível das águas do lago da UHE da Capivara baixava e, até o momento, continua sendo a única forma de realizarmos pesquisas no local que estamos visitando regularmente, também porque, sempre que o nível das águas baixa, a população de lepê cobra nossa presença. Trata-se de uma população de aproximadamente 7.000 habitantes, fortemente engajada na preservação desse patrimônio arqueológico, que reconhecem como seu. 


\section{A Etno-história do Vale do Rio Paranapanema: os Guarani}

Quando tratamos da etno-história da área do Vale do Rio Paranapanema, deparamo-nos com a dificuldade de reunir bibliografia sobre as ocupações indígenas existentes na área do Rio Paranapanema, margem paulista, a partir do século XVI. Dos séculos XVI e XVII, contamos apenas com relatos dos cronistas, viajantes, missionários e funcionários da Coroa, notadamente sobre a presença dos Guarani. Quanto à presença dos Guarani na margem paulista do Rio Paranapanema, os dados mais importantes foram aqueles coligidos em publicações que trataram mais especificamente do seu lado paranaense, mas que fizeram alguma referência ao lado paulista. Tratam de relatos de missionários jesuítas ou de relatos relacionados às reduções jesuíticas. Os dados são escassos no que diz respeito a informações específicas sobre a área em estudo.

Dos séculos XIX e XX temos os trabalhos de historiadores, etnólogos, jornalistas, documentos (como cartas e mapas) e a história oral sobre a presença de grupos Guarani, Kaingang e Xavante. Do lapso de tempo intermediário (segunda metade do século XVII e século XVIII) não se têm, até o momento, informações sobre as ocupações indígenas da área.

Os dados fornecidos pela etno-história fundamentam pesquisas arqueológicas, como foi os caso das realizadas nos Sítios Arqueológicos Taquaruçu, Taquaruçu II e Alvim, localizados na área do Baixo Paranapanema Paulista, associados, respectivamente, às reduções indígenas Maracaná, Itamaracá e Araraá. Dados fornecidos pela etno-história dos guarani auxiliam, muitas vezes, na compreensão do registro arqueológico. Ainda que se tenha em mente que a cultura é dinâmica, nota-se, no caso dos guarani, a manutenção de certas características da cultura material (Noelli 1993).

Tendo em vista essa escassez de dados etno-históricos sobre os índios que ocuparam a área do Vale do Rio Paranapanema Paulista (área do ProjPar - Projeto Paranapanema), avaliamos a grande importância dos registros arqueológicos, sem os quais pouco - ou quase nada - se saberia sobre os guarani, precursores na ocupação dessa área.

Os sete sítios arqueológicos guarani de Iepê, SP: a questão da preservação nas áreas do Lago da Hidrelétricas da Capivara

A preservação dos sítios arqueológicos, apesar de protegidos pela Constituição Federal, depende de uma política eficiente de proteção que torne viável sua conservação, da existência ou disposição de órgãos ou empreendimentos que financiem as pesquisas e da atuação de um maior número de profissionais arqueólogos. A não preservação do ambiente onde estão inseridos os sítios arqueológicos, como é o caso da área onde estão localizados os sítios arqueológicos em estudo, causa a destruição do registro arqueológico, dano irreparável à memória nacional.

Os inúmeros avanços tecnológicos conquistados pelo homem não têm conseguido conter a degradação do ambiente e do patrimônio cultural. Se, por um lado, as conquistas no âmbito da técnica têm propiciado o aperfeiçoamento dos trabalhos e a utilização de equipamentos eficientes, por outro, têm colaborado para a degradação ambiental, sobretudo quando se fala em construção de usinas hidrelétricas e manejo dos solos. Essas questões têm interferido na preservação do ambiente e do patrimônio arqueológico nele contido. O patrimônio nem sempre encontra espaço para preservação, apesar de ser um bem protegido pela União.

A área dos sítios arqueológicos do Município de lepê, em tela, foi impactada pela construção da Usina Hidrelétrica da Capivara, cujo lago inundou a área de sítios arqueológicos no ano de 1974. A formação do Lago da Capivara aconteceu sem que o resgate dos sítios arqueológicos tivesse sido realizado pela CESP (Companhia Energética do Estado de São Paulo). A água do lago inundou a área total dos registros arqueológicos dos Sítios Capisa e Terra do Sol Nascente, deixando-a submersa e, em alguns meses de alguns anos, em faixa de depleção, os Sítios Lagoa Seca, Pernilongo, Aguinha, Ragil e Ragil II. O Sítio Ragil II, por exemplo, 
raramente emerge - a última ocorrência foi no ano de 1998. Os Sítios Lagoa Seca, Pernilongo e Aguinha, em alguns períodos de seca de alguns anos, ficam com apenas parte da sua ocupação emersa. O único sítio que possui parte de sua área o ano todo fora da influência dos avanços e recuos do lago da UHE da Capivara, é o Ragil. $\mathrm{Na}$ área dos sete sítios de Iepê, lidamos, em todos os casos, com sítios alterados pela ação hídrica e ações decorrentes do manejo da terra e pisoteio de gado.

O Sítio Ragil está localizado em área utilizada para plantio, embora, mais recentemente atualmente, a parte fora da área de inundação seja usada exclusivamente para pastagem. Ainda há uma estrada de terra que corta esse sítio. Com isso, mesmo estando parte fora da área de inundação, os impactos nesse terreno são relevantes. Dos sítios arqueológicos de Iepê em análise, o Sítio Ragil é o que apresenta a cerâmica em pior estado de conservação. São peças ressecadas, com barbotina craquelada, onde a decoração pintada, se realmente ocorreu, dificilmente pode ser vista.

Quando comparamos os fragmentos cerâmicos do Sítio Ragil com os dos Sítios Pernilongo, Aguinha, Lagoa Seca e outros, verificamos, nesses últimos, fragmentos em melhor estado de conservação. São fragmentos maiores e apresentam barbotina intacta. Isso porque a fragmentação causada pela ação da água parece ser menos agressiva que a ação causada por arado, subsolador, pisoteamento de gado ou esmagamento por pneus de carro ou de trator.

Com relação à dureza da cerâmica, todos esses sítios apresentam, no geral, dureza três (escala de Mohs). Contudo, verificamos que cerâmicas com queima baixa ficam muito frágeis depois de quase três décadas imersas na área do lago da UHE da Capivara.

Os sítios localizados na área do Lago da UHE da Capivara têm os registros arqueológicos imersos na água, por isso, o sedimento presente sobre as tampas das urnas funerárias fica mais pesado, ao mesmo tempo em que água e sedimentos penetram na urna. Depois de preenchido o interior da urna com sedimento, o processo pode ficar estável, se uma camada de sedimento estiver sobre a peça. Contudo, o sedimento úmido dentro da vasilha pode forçar suas paredes, provocando rachaduras que são preenchidas por sedimentos.

Se, em um momento posterior, a camada de sedimento sobre a tampa da urna for retirada, no processo de avanço e recuo das águas do lago, na alternância entre períodos chuvosos e períodos secos, a tampa, que já está fragmentada, tem as partes da base levadas pela água. Na sequência, a tampa e a urna começam a perder fragmentos da borda. Quando a vasilha tem altura muito maior que o diâmetro da boca, como é o caso do yapepó, pode ocorrer de as rachaduras serem no sentido mais longitudinal e, dessa forma, provocarem a divisão da peça em duas metades.

No caso de formas como o cambuchi, as rachaduras são irregulares. Podemos citar como exemplo o cambuchi do sítio arqueológico Aguinha. É obvio, portanto, que se evidenciamos as vasilhas logo depois que o sedimento sobre a tampa foi retirado, seu estado de conservação é melhor. Nesse caso, elas, por vezes, não estão rachadas e, quando estão, é possível restaurá-las em laboratório, pois as partes ainda permanecem em posição original.

Quando as águas levam a tampa e pedaços da borda; eles podem ser encontrados enterrados em pontos bem distantes, uma vez que já encontramos fragmentos de vasilhas a 300 metros da posição original.

O processo de retrabalhamento das margens pelas correntes de fundo desestrutura o pacote sedimentar que contém, no seu interior, os registros arqueológicos. Os processos coluviais, aluviais e hídricos, desencadeados na área pelo escoamento de superfície, causam o deslocamento dos vestígios e, portanto, modificam a feição original do sítio.

Embora não queiramos, de forma alguma, defender a presença de vasilhas arqueológicas na área de lagos de hidrelétricas, é importante registrar o fato de essas vasilhas estarem em melhor estado de conservação na área do lago do que nas áreas de plantio, pastagem ou estradas.

$\mathrm{Na}$ análise do material cerâmico, as tentativas de agrupar fragmentos de superfície em conjuntos de um mesmo vaso raramente deram bons resultados nas áreas de influência de lagos de UHEs, a não ser nos casos em que o nível 
d'água baixou rapidamente, deixando uma vasilha, recém-fragmentada praticamente na mesma posição. Contudo, em casos de a vasilha fragmentada ficar por alguns dias em área de depleção, sob a ação do vai e vem das águas do lago, sua posição provavelmente se alterará.

$\mathrm{Na}$ área do lago da UHE da Capivara, certamente, estão parte dos últimos exemplares de cerâmica guarani do Estado de São Paulo, tendo em vista que depois da década de 1980, com o avanço da agricultura mecanizada, é muito difícil encontrar vasilhas cerâmicas indígenas inteiras nas áreas de sítios arqueológicos. O manejo do solo, não raramente, tem por consequência, processos erosivos que removem e sulcam as camadas estratigráficas que contêm vestígios de ocupações indígenas pretéritas. Por consequência, o uso do arado e do subsolador consiste, atualmente, em grande problema para a conservação de sítios arqueológicos.

A agricultura, a pastagem e o empreendimento das usinas hidrelétricas, em áreas de sítios arqueológicos, têm causado problemas às pesquisas, pois dificultam respostas satisfatórias para questões que, nas décadas de 1960 e 1970, eram de mais simples solução - como, por exemplo, a localização de manchas pretas na sua relação com as urnas funerárias, ou o conhecimento do contorno das vasilhas, tendo em vista que tínhamos a área dos sítios e as vasilhas preservadas das ações do arado, subsolador e das inundações.

Assim, se os sítios de lepê, SP tivessem a sua proteção e resgate garantidos, antes da formação do lago da UHE da Capivara (1974), conforme dispõe a Lei 3.924 (de 27 de junho de 1961), certamente hoje teríamos, sobre esses sítios, informações tão importantes como as que temos de sítios Guarani como o Almeida ou o Alves, pesquisados por Pallestrini (1975).

Verificamos, nas áreas dos sítios arqueológicos em análise, grande potencial de informações, mesmo conhecendo, apenas, parte (que, na nossa avaliação, são as menores) dos sítios, pois a maior parte de cada um deles está imersa na área do Lago da UHE da Capivara - com exceção do Sítio Ragil que apresenta, como já citado, menor área imersa.

Hoje, sabemos dos danos que o empreendimento da Usina Hidrelétrica da Capivara cau- sou - e está causando - aos sítios arqueológicos de Iepê localizados na área do seu lago. Afirmamos isso tendo em vista a riqueza dos registros arqueológicos e o fato de os sítios apresentarem registros, em estado de conservação cada vez pior no Estado de São Paulo. Compomos a equipe do ProjPar desde 1983 e, a partir de então, vimos poucos sítios com potencial arqueológico como os do Município de lepê, SP.

As consequências da construção de empreendimentos, do nível de uma hidrelétrica, possuem uma amplitude temporal que se inicia com a construção e continua ao longo de sua existência, haja vista o dano provocado, ainda hoje, pelo constante avanço e recuo das águas do lago da UHE da Capivara, nos sítios arqueológicos de Iepê.

A CESP deveria, antes da formação do Lago da Usina Hidrelétrica da Capivara, ter promovido o salvamento dos sítios arqueológicos que estavam dentro da cota de inundação do seu lago. Apesar de o salvamento sistemático não ter ocorrido, o Sr. Roberto Ekman Simões coletou, em superfície, as únicas peças hoje conhecidas do Sítio Arqueológico Capisa, assim como a maior parte das peças do Sítio Terra do Sol Nascente.

No entanto, de pouco adiantam as leis, as políticas de preservação, os financiamentos e a disponibilidade de arqueólogos, se as pessoas que se deparam com o patrimônio arqueológico não souberem de sua importância e não lutarem pela garantia de sua preservação. No Município de Iepê, temos exemplos de cidadania nas pessoas de todos aqueles que, de alguma forma, colaboraram para que o Museu de Arqueologia do município fosse instalado, garantindo proteção, estudo, guarda e exposição a todos os registros arqueológicos resgatados.

\section{Os Sítios Arqueológicos Guarani do Município de Iepê, SP}

Nos casos dos sítios Guarani, estudados no Município de Iepê, a área investigada não corresponde à área total do sítio, pois parte dela está submersa nas águas do Lado da Hidrelétrica da Capivara, mesmo nos períodos de 
seca, quando o nível das águas baixa. No caso do Baixo Paranapanema, só conseguiremos ter uma resposta para a investigação completa desses sítios se trabalharmos com as técnicas da arqueologia subaquática.

Com os estudos realizados conhecemos parte dos registros das ocupações de cada um dos sítios Guarani. Apesar das limitações, podemos afirmar que, esses, em muito se parecem com os registros dos sítios no Médio e Alto Paranapanema, pesquisados no âmbito do ProjPar, desde a década de 1960.

Na área do Sítio Alves, Pallestrini (1974, 1975) evidenciou sete manchas pretas e cinco urnas funerárias. As manchas têm a forma oval, dispostas em "U”, com a parte aberta para o Ribeirão Alves. As urnas foram encontradas dispostas, de forma dispersa, na entra$\mathrm{da}$, entre as duas primeiras manchas pretas que formam o "U", com a parte aberta para o sul. No Sítio Nunes, Pallestrini (1988), evidenciou três manchas pretas, novamente dispostas na forma de "U", com a parte aberta para o córrego, também no sentido sul.

No Sítio Prassévichus, Pallestrini (1986) evidenciou nove manchas pretas e oito urnas funerárias. As manchas e as urnas estão dispostas de forma irregular sobre a área do sítio, não parecendo obedecer a um padrão. O Sítio Fonseca apresentou oito manchas pretas e cinco urnas funerárias (Pallestrini 1975). Suas manchas pretas estão dispostas na forma de "ferradura", com a abertura voltada para leste. A disposição das urnas não parece obedecer a qualquer padrão.

O Sítio Jango Luiz apresentou dez manchas pretas e pelo menos três urnas funerárias (Pallestrini 1975). A disposição das manchas pretas e das urnas funerárias não parece obedecer a qualquer padrão. No Sítio Almeida, Pallestrini (1975) evidenciou nove manchas pretas e cinco fogueiras. As manchas pretas parecem formar um "U", com abertura para leste. As fogueiras não apresentam um padrão de localização em relação à disposição das casas. Apenas uma das quatro fogueiras foi evidenciada em área de mancha preta. Todos esses sítios, analisados por Pallestrini (1975), foram localizados em áreas próximas a um córrego ou ribeirão.
Fora da área da Bacia do Rio Paranapanema, Faccio (2010) evidenciou o Sítio Célia Maria, na Bacia do Rio Aguapeí, contendo três manchas pretas. Sítios com três manchas pretas foram pouco estudados na área do ProjPar e fora dele. $\mathrm{O}$ estudo desse tipo de sítio é raro. $\mathrm{Na}$ área do Baixo Paranapanema, até o momento, nenhum sítio com três manchas pretas foi encontrado. Contudo, esse tipo de sítio pode ocorrer na área, tendo em vista que nem todas as áreas do Baixo Paranapanema foram estudadas de forma sistemática. Os sítios com menos de três manchas pretas são, de modo geral, pouco conhecidos dentro da arqueologia guarani. Já os sítios com mais de três habitações são comuns na área do Vale do Rio Paranapanema.

As habitações guarani, no geral, apresentam forma oval, dispostas de forma irregular dentro da área da aldeia. Essas manchas, portanto, são os testemunhos da área de antigas habitações que, depois de abandonadas, apodreceram, deixando no solo as marcas de seu passado. Nesses locais, os índios faziam suas fogueiras para garantir o aquecimento e afugentar os insetos; isso também enegrecia o solo. Contudo, dos sítios apresentados por Pallestrini $(1974,1975)$ apenas um apresentou fogueira na área de uma das manchas pretas.

Nos casos dos sítios Guarani, da área do Baixo Paranapanema, os mais conhecidos são o Alvim, o Itororó, o Neves e aqueles localizados no Município de Iepê, SP.

O sítio Alvim, localizado no Município de Pirapozinho, SP, pelo seu estado de conservação, não possibilitou a identificação de nenhuma estrutura de fogueira ou mancha preta. No entanto, pela quantidade de material evidenciado fora de posição original, deduzse ter sido uma grande aldeia guarani (Faccio 1992). O Sítio Neves, localizado no Município de Rancharia, SP, apresentou uma única mancha preta. Ao que tudo indica, este foi um sítio de ocupação de curta duração ou sazonal (Faccio 1998). O Sítio Itororó (também no município de Pirapozinho, SP) apresentou três vasilhas cerâmicas, do tipo cambuchi cabaguá, duas delas contendo ossos de crânio de criança (Kashimoto 1992). 
Os sítios Guarani de Iepê, SP, estão localizados próximos ao Rio Paranapanema e/ou seus afluentes, cobrindo um raio de 10.800 metros. Os Sítios Lagoa Seca e Aguinha possuem grandes lagoas no entorno (500 e 200 metros de distância da área dos sítios, respectivamente) (Faccio 2011).

O Sítio Lagoa Seca apresentou uma mancha preta de 3,5 por 7 metros e uma urna funerária com tampa, contendo outra vasilha no seu interior. Na área da mancha preta foi evidenciada uma fogueira contendo blocos de pedra e cinzas. Essas são as únicas estruturas que conhecemos da área do Sítio Lagoa Seca. O restante, certamente, está imerso nas águas do lago da UHE da Capivara.

O Sítio Aguinha apresentou seis urnas funerárias dispostas de forma esparsa pela área do sítio, uma mancha preta distante da área das urnas e uma fogueira contendo blocos de pedra e carvão, aparentemente longe das áreas de enterramento. Analisando a localização dos registros arqueológicos pela área do sítio e conhecendo a "decapagem assistemática", realizada pelas águas do lago da UHE da Capivara, ao longo dos anos, na área do sítio, bem como as características de outros sítios guarani da área do ProjPar, levantamos a hipótese de que essa área possuía muitas outras manchas pretas, tendo sido solapadas por "decapagens" provocadas pelas correntes de fundo. Isso porque, quando encontramos as urnas, elas estavam sem a camada de sedimentos, estimada em pelo menos 15 centímetros, que as cobriam. Já as manchas pretas, quando evidenciadas, possuem entre 15 e 18 centímetros de espessura.

O Sítio Terra do Sol Nascente não apresentou nenhuma estrutura de atividade humana no pequeno período em que esteve emerso. Poucas intervenções foram realizadas na área. Durante a coleta sistemática de superfície na área desse sítio encontramos um tembetá em quartzo e um naembé, ambos fora da posição original.

O Sítio Pernilongo apresentou três urnas funerárias e outras quatro vasilhas, provavelmente utilizadas também como urnas funerárias. Evidenciamos, no local, adornos em resina de jatobá. Essas vasilhas poderiam ser usadas para, provavelmente, enterramento secundário, tendo em vista seu menor tamanho. Ou, então, para o enterramento de cabeças, como ocorreu no Sítio Itororó (Pirapozinho, $\mathrm{SP})$. Não notamos, ali, nenhuma mancha preta, provavelmente porque estas foram solapadas por "decapagens assistemáticas", provocadas pelas correntes de fundo do lago da UHE da Capivara.

O Sítio Ragil, apesar de ter sua maior parte fora da área de inundação do lago da UHE da Capivara, está coberto por pastagem. Dessa forma, apesar de termos realizado sondagens na área, não evidenciamos manchas pretas, embora estas, provavelmente, existam. Quanto ao material cerâmico desse sítio, encontra-se muito fragmentado. Apenas um fundo de yapepó, provavelmente utilizado para enterramento, foi encontrado. Dessa forma, para a área deste sítio, não podemos precisar a localização de urnas ou manchas pretas que, supomos, tenham sido muitas.

Do Sítio Capisa, totalmente imerso nas águas do lago da UHE da Capivara, não temos outras informações além dos fragmentos cerâmicos coletados por Roberto Ekman, antes da formação do lago da UHE Capivara.

O Sítio Ragil II, por sua vez, apresentou três manchas pretas, de tamanhos diferentes. $\mathrm{Na}$ área de pastagem, ao fundo das manchas pretas, realizamos sondagens e evidenciamos, de forma esparsa, apenas fragmentos de cerâmica. O sítio parece estar localizado, a partir das manchas pretas, em direção à área do lago.

Além das manchas pretas, urnas funerárias e fogueiras, foram encontrados nas áreas desses sítios fragmentos de cerâmica, líticos lascados e ou polidos, dispostos de forma caótica sobre a superfície. Contudo, não podemos afirmar que essa área de dispersão do material em superfície seja a área do sítio, ainda que, em alguns casos, a dispersão do material em superfície coincida com a área original do registro arqueológico.

Somente na área do Sítio Pernilongo foi encontrado adorno em resina de jatobá. Somente a área do Sítio Capisa não emerge em nenhuma época do ano.

Do exposto, observamos que é difícil inferir as dimensões e forma dos sítios Guarani 
em análise, bem como o número de manchas pretas, de urnas funerárias ou de fogueiras. Contudo, essas aldeias guarani do Município de Iepê parecem ter grandes dimensões e, provavelmente, devem ser parecidas, em sua organização espacial, com aquelas evidenciadas por Pallestrini (1975).

A cerâmica Guarani da área do ProjPar apresenta rica variabilidade e particularidades, quando comparamos os materiais dos diferentes sítios. São comuns os tipos liso, pintado, corrugado, inciso, escovado, mamilar, serrungulado, ponteado, entalhado entre outros. A porcentagem em que ocorre cada um desses tipos varia de um sítio para o outro. $\mathrm{Na}$ área do Baixo Vale do Rio Paranapanema, não foi diferente. Conforme afirma Pallestrini (1975):

\footnotetext{
"Cada sítio novo tem características peculiares, com analogias e diferenças marcantes e significativas em relação ao anterior. Entre outros um exemplo que poderia ser citado seria o das diferenças tipológicas e percentuais da cerâmica entre os sítios, diferenças essas que levam a novos aspectos do facies cerâmico na área do Rio Paranapanema do Estado de São Paulo" (Pallestrini 1975: 56).
}

\section{Essa variabilidade é vista em muitos} elementos que constituem a cerâmica Guarani, ainda que, para o caso de Iepê, tenhamos que estar atentos para o fato de lidarmos, em cada um dos sítios, apenas com parte dos registros.

Quando analisamos a forma, o tamanho e o tipo de tratamento de superfície das urnas funerárias e materiais associados a essas urnas verificamos sua grande variabilidade. Quando analisamos os motivos mínimos pintados em cada vasilha notamos semelhança. Contudo, a forma como esses motivos são organizados de um sítio para outro, em muitos casos, apresenta diferenças.

$\mathrm{Na}$ área dos sítios em análise, o antiplástico utilizado foi o mineral associado ao caco moído. O uso exclusivo do antiplástico mineral ocorre, sempre, numa porcentagem, menor que $7 \%$, em vasilhas de parede fina e de pequeno tamanho. A espessura das paredes variou de 0,3 a 4,9 centímetros. A espessura do antiplástico variou de 0,1 a 0, 6 milímetros. $O$ alisamento das partes internas e externas, bem como o uso de barbotina, também foi comum nas peças dos sítios em análise.

Percebemos que a cerâmica Guarani dos sítios em estudo, muitas vezes, associa o tipo simples com um ou mais tipos de decoração, configurando uma decoração zonada. As decorações pintadas são realizadas na parte interna e/ou externa dos vasos, respeitando a forma. Os tipos pintados são policrômicos em preto, vermelho e marrom, sobre engobo branco, compostos por motivos mínimos. Uma vasilha pode apresentar um ou mais motivos mínimos, que se repetem de diferentes formas. É comum o espelhamento nos sentidos vertical e horizontal. O tipo e a quantidade de motivos mínimos variaram de um sítio para o outro. Contudo, somente para três, dos sete sítios guarani, conseguimos identificar os motivos mínimos. Optamos por trabalhar com motivos mínimos ao invés de fazer descrições utilizando conceitos geométricos, tendo em vista nossa suposição de que esses motivos mínimos possuem significados para os índios Guarani, ainda que não saibamos qual seja exatamente esse significado. Nosso interesse, foi o de fazer uma boa arqueografia dos motivos para, no futuro, discutir, de forma mais aprofundada, possíveis interpretações com base em registros etnográficos.

$\mathrm{Na}$ figura 2 apresentamos os motivos mínimos identificados na cerâmica guarani dos Sítios Lagoa Seca, Aguinha e Pernilongo. Quando comparamos os motivos levantados por Schimitiz (1980) com os levantados para os Sítios Lagoa Seca, Aguinha e Pernilongo vemos semelhanças, mas também particularidades. Contudo, isso não nos surpreende, pois os motivos identificavam os diferentes grupos Guarani.

As pinturas parecem ter sido aplicadas com pincel (para linhas: espinhos, bico de pena, finas taquaras) ou com o dedo (faixas), sobre fundo engobado branco ou creme. As pinturas são formadas por um ou mais motivos mínimos. Os motivos mínimos são constituídos por linhas ou faixas, retas ou sinuosas, 


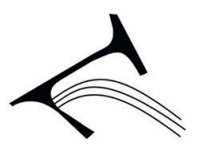

Sítio Lagoa Seca No: 1933
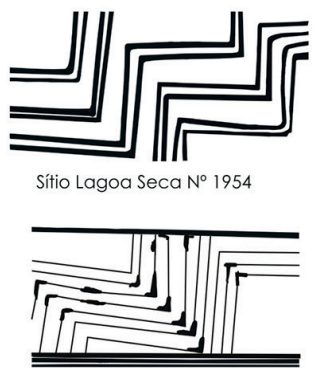

Sítio Lagoa Seca No 1944

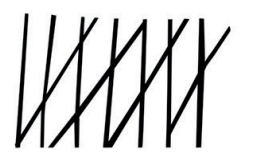

Sítio Lagoa Seca No 2342

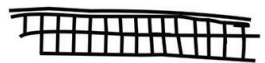

Sítio Lagoa Seca № 2221

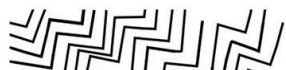

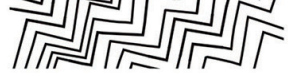
Sítio Lagoa Seca № 3505

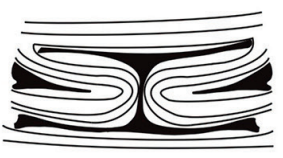

Sítio Aguinha $N^{\circ} 5608$

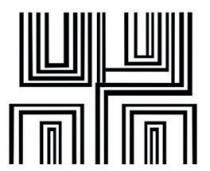

Sítio Aguinha $\mathrm{N}^{\circ} 2120$

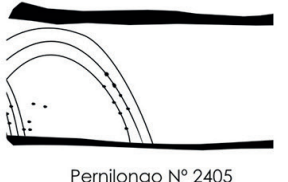

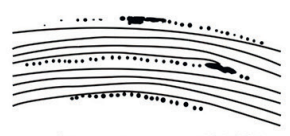

Sítio Lagoa Seca No 1935

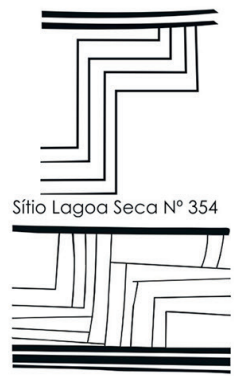

Sítio Lagoa Seca No 1944
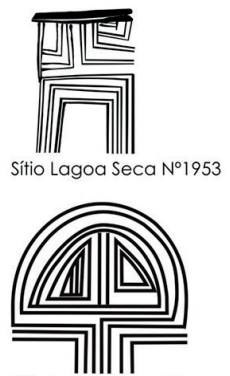

Sítio Lagoa Seca No 1949
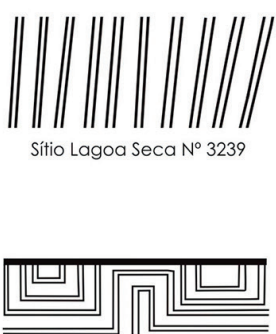

Sítio Aguinha $\mathrm{N}^{\circ} 2669$

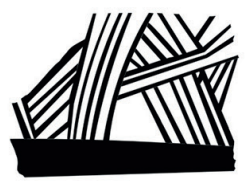

Sítio Aguinha № 5528

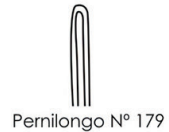

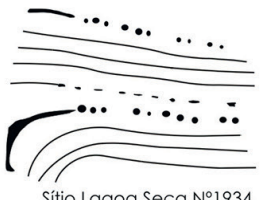

Sítio Lagoa Seca №1934

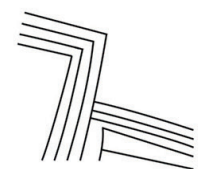

Sítio Lagoa Seca $N^{\circ}-2202$

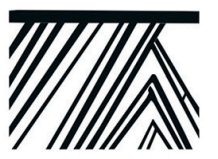

Sítio Lagoa Seca No 196
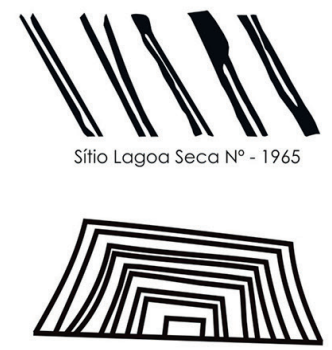

Sítio Lagoa Seca N 1931

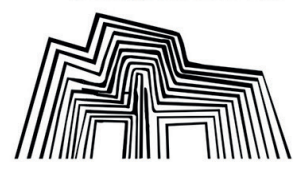

Sítio Lagoa Seca No 1970

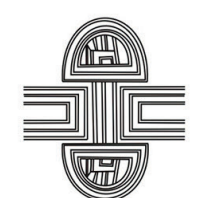

Sítio Lagoa Seca No1366
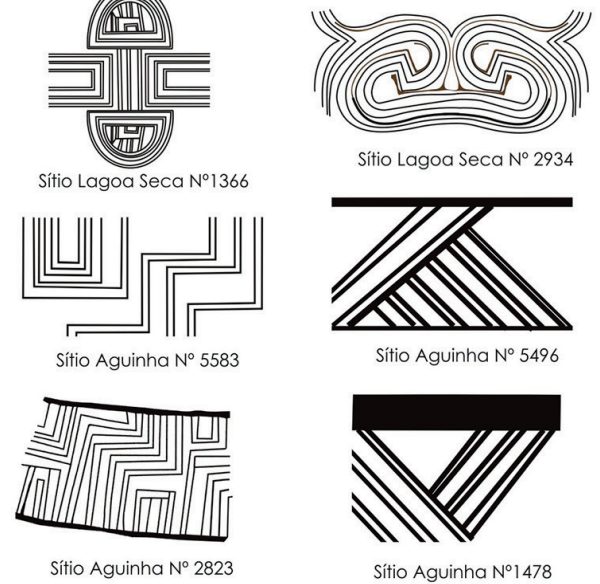

Sítio Aguinha $N^{\circ} 5496$

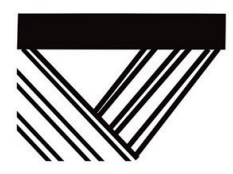

Sítio Aguinha $N^{\circ} 1478$

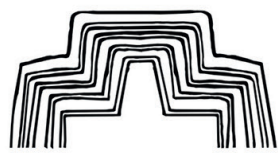

Sítio Aguinha $N^{\circ} 2821$

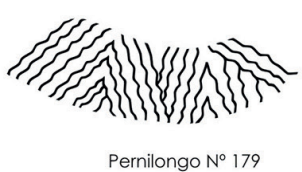

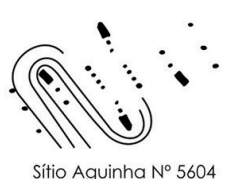

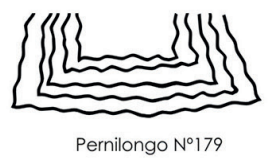

Fig.3. Motivos mínimos da cerâmica guarani dos sítios arqueológicos Penilongo, Aguinha e Lagoa Seca.Município de Iepê, SP. 
contínuas ou pontilhadas. Também apesentam, com alguma frequência, pontos. Os motivos mínimos variaram de um sítio para outro, caracterizando, provavelmente, preferências do grupo ou mudanças no tempo.

Nos nãmôpy, é comum a pintura nas faces interna ou na externa e, mais raramente, nas duas faces da mesma peça. Nos cambuchi, o comum é a pintura na face externa. $\mathrm{O}$ engobo é comum na face interna de vasilhas como nãmôpy e cambuchi cabaguá. Os cambuchi e os cambuchi cagabá sempre apresentaram, nas peças analisadas dos sítios de lepê, motivos pintados e engobo.

São comuns, na cerâmica da área dos sítios em análise, furos nas paredes das vasilhas, confeccionados depois da vasilha queimada, ou seja, pronta. Esses furos circulares, por vezes, são evidenciados um ao lado do outro, o que sugere que tenham sido usados para amarrar as partes de uma vasilha com rachaduras ou fragmentada. Esses furos, confeccionados em paredes de maior espessura, também sugerem que, para essas vasilhas, o "conserto" compensava. Furos próximos à borda também foram verificados, com frequência, em vasilhas menores. Esses furos foram feitos antes da queima da vasilha, o que indica um planejamento de uso, certamente o de suspender a vasilha com corda. Também é comum a utilização de fragmentos de cerâmica ou plaquetas de arenito como amolador ou calibrador.

As datações absolutas para a área dos sítios de Iepê, SP são relacionadas na tabela 1 .

\begin{tabular}{l|c}
\hline \multicolumn{1}{c|}{ Sítio } & Datação \\
\hline Lagoa Seca & $770 \pm 70$ \\
\hline Aguinha & $700 \pm 160$ \\
\hline Pernilongo & $750 \pm 110$ \\
\hline Terra do Sol Nascente & $750 \pm 80$ \\
\hline Ragil & $\begin{array}{c} \pm 1668 \text { (AD ? Qual } \\
\text { é o intervalo do } \\
\text { desvio padrão?) }\end{array}$ \\
\hline Capisa & $850 \pm 150$ \\
\hline Ragil II & $900 \pm 180$ \\
\hline
\end{tabular}

Tabela 1: Datações dos sítios Guarani estudados. Município de Iepê, SP
As datações obtidas para os sítios Guarani do Vale do Rio Paranapanema estão dentro do lapso de um intervalo de 1.000 anos, já amplamente divulgada para a área do ProjPar. Analisando as datas obtidas para os sítios Guarani do Município de Iepê, SP, verificamos que os Sítios Pernilongo e Terra do Sol Nascente possuem a mesma idade. O raio que separa a área dos A distância entre os dois sítios é de 2.400 metros, estando entre eles o Córrego da Estiva. O Sítio Terra do Sol Nascente forneceu, até o momento, poucos dados. O que temos da área desse sítio são fragmentos de cerâmica coletados assistematicamente por Roberto Ekman Simões, antes da formação do lago da UHE da Capivara, além de um pequeno naembé, coletado em superfície fora da posição original.

A princípio, somente com a análise do material cerâmico, não poderiamos indicar relações entre os dois sítios. Contudo, fazendo uma comparação entre os aspectos tecnológicos das duas produções cerâmicas, verificamos semelhanças na técnica de produção. Necessitamos, no entanto, de mais elementos para comparar forma e decoração das vasilhas.

Os Sítios Capisa e Ragil II apresentam uma difereça de idade de aproximadamente 50 anos. Os motivos da decoração pintada desses dois sítios não são semelhantes. Aliás, a decoração pintada do Sítio Capisa destaca-se em relação às dos demais sítios de Iepê pelo uso do preto e de faixas. Contudo, para a área desses dois sítios, não conseguimos identificar os motivos mínimos.

Já a datação para a área do sítio arqueológico Ragil destoa das anteriores, indicando não haver relação entre esse sítio e os demais. De fato, já destacamos, que a cerâmica desse sítio difere das dos demais sítios Guarani de Iepê, em análise, principalmente no que diz respeito à técnica de acabamento. Contudo, as formas são bastante semelhantes a dos demais sítios.

Na cerâmica dos sítios em análise, verificamos o uso da brunidura em poucos casos. Sabemos que essa é uma técnica de grupo Kaingang. Mas, também, sabemos que a cerâmica Kaingang possui espessura de parede muito mais 
fina que a guarani. Dessa forma, essa brunidura pode ser não intencional, ou foi aprendida por alguma forma de contato, cuja discussão não nos é possível levantar agora.

Quando analisamos os tipos cerâmicos dos sítios em tela, verificamos muitas semelhanças na forma, tamanho, tipo de antiplástico, além do predomínio do tipo liso.

Mesmo não sendo o nosso objetivo tratar aqui dos líticos lascados, consideramos importante colocar que a técnica de lascamento utilizada por esses índios guarani foi comumente a percussão direta com percutores duros, resultando em peças com secção planoconvexa, que tinham os seus bordos retocados de acordo com a função que pretendiam. A utilização de percutores macios é registrada com pouca frequência (Morais 1983; Faccio, 1992). Observamos uma indústria do lítico lascado sobre seixo nas áreas dos sítios Guarani em estudo, com predomínio do arenito silicificado como matéria-prima. Nota-se, na indústria lítica dos sítios Guarani em análise, uma grande quantidade de resíduos, frutos de uma técnica de lascamento que primou pela utilização do aquecimento térmico. Constatamos, também, que os produtos de talhe e debitagem são pouco retocados.

\section{Conclusão}

Essas considerações buscam sistematizar e apresentar algumas inferências acerca dos trabalhos realizados nos sítios de lepê, SP. No entanto, restam, sobretudo, hipóteses e perspectivas de novas etapas de trabalho, a fim de que possamos avançar no conhecimento das populações pretéritas que ocuparam aquela área. Tal empreitada nos motiva, haja vista a riqueza e complexidade que os sítios guarani de Iepê contemplam.

A oportunidade de apresentar este artigo marca o momento de nossos estudos na arqueologia, ocasião de mais interrogações que certezas, o que só nos instiga a prosseguir. A crença de fazer avançar, o pouco que seja, o conhecimento da arqueologia do Vale do Paranapanema, com nossa contribuição - em parte, materializada neste artigo - nos anima a enfrentar os muitos desafios que o ofício de arqueólogo apresenta no Brasil de hoje.

\section{Agradecimentos}

Agradeço ao Professor e Arqueólogo José Luiz de Morais pelos ensinamentos e pela oportunidade de trabalhar no ProjPar, desde 1983.

FACCIO, N.B. The Archaeological Sites Guarani Municipality Iepê, SP. R. Museu Arq. Etn., 25: 119-131, 2015

Abstract: The research conducted in the area of seven Archaeological Sites located in Iepê, municipality of São Paulo State (region of Paranapanema Basin, tributary of Paraná Basin), demonstrated a pre-colonial Guarani occupations. The pottery was dated by thermoluminescence method, identifying occupations in the period 700-1668 years before present. This paper presents data on ceramic faced with data from other researches available that were about the presence of Guarani in the Paraná and Paranapanema Basins.

Key-words: Guarani Archaeology; ceramic analysis; Paranapanema Basin. 


\section{Referências bibliográficas}

Faccio, N.B. 1992. Estudo do Sítio Arqueológico Alvim no Contexto do Projeto Paranapanema. Dissertação de Mestrado. São Paulo: Faculdade de Filosofia, Letras e Ciências Humanas, USP.

Faccio, N.B. 1998. Arqueologia dos Cenários das Ocupações da Capivara, Baixo Paranapanema. Tese de doutorado. São Paulo: Faculdade de Filosofia, Letras e Ciências Humanas, USP.

Faccio, N.B. 2010. Relatório de Resgate do Sitio Célia Maria (não publicado). Presidente Prudente: Universidade Paulista, Laboratório de Arqueologia Guarani.

Faccio, N.B. 2011. Arqueologia Guarani na Área do Projeto Paranapanema: estudo dos sítios de Iepê, SP. Tese de livre docência. São Paulo: Museu de Arqueologia e Etnologia, USP.

Kashimoto, E.M. 1992. Geoarqueologia no Baixo Paranapanema: uma pesquisa geográfica de estabelecimentos humanos pré-históricos. Dissertação de mestrado. São Paulo: Faculdade de Filosofia, Letras e Ciências Humanas, USP.

Morais, J.L. 1983. A utilização dos afloramentos litológicos pelo homem pré-histórico brasileiro: análise do tratamento da matéria-prima. Coleção Museu Paulista (série de Arqueologia) 7, 212p.
Morais, J.L. 2002. Resgate arqueológico na área de influência da duplicação das rodovias SP 342 e SP 346: preservação do patrimônio dos Sítios Ipê e Mota Pais (não publicado). Mogi Guaçu: Relatório Técnico Científico Final.

Noelli, F.S. 1993. Sem Tekoá não há Tekó. Em busca de um modelo etnoarqueológico da aldeia e da subsistência guarani e sua aplicação a uma área de domínio no Delta do Jacuí. Dissertação de mestrado. Porto Alegre: Pontifícia Universidade Católica do Rio Grande do Sul.

Pallestrini, L. 1975. Interpretação das estruturas arqueológicas em sítios do Estado de São Paulo. Coleção Museu Paulista (Série Arqueologia) 1, 208p.

Pallestrini, L. 1974. Sítio Alves. Revista do Museu Paulista: 47-96.

Pallestrini, L. 1980. A Tradição Tupiguarani: a subtradições e sua origem. In: Schmitz, P.I.; Barbosa, A.S.; Ribeiro, M.B. Temas de Arqueologia Brasileira. Goiânia: IGPA.

Pallestrini, L. 1988. Projeto Paranapanema: Sítio Arqueológico Nunes - Estado de São Paulo. Revista do Museu Paulista (Nova Série) XXXIII: 129-142. 